\title{
Synthesis of Serving Policies for Objects Flow in the System with Refillable Storage Component
}

Fedosenko, Y.S., Miroshina, A.S., Pudov, A.S., Plekhov, A.S., Chakirov, R. and Houlden, N

This is a paper presented at the 7th IEEE Int. Conference on Internet Technologies and Applications ITA-17, Wrexham, UK, 12-15 September 2017.

Copyright of the author(s). Reproduced here with their permission and the permission of the conference organisers.

\section{Recommended citation:}

Fedosenko, Y.S., Miroshina, A.S., Pudov, A.S., Plekhov, A.S., Chakirov, R. and Houlden, N (2017) 'Synthesis of Serving Policies for Objects Flow in the System with Refillable Storage Component'. In: Proc. 7th IEEE Int. Conference on Internet Technologies and Applications ITA-17, Wrexham, UK, 12-15 September 2017, pp. 185-188. doi: 